\section{Liebe Mitglieder der DFR, sehr verehrte Frau Kollegin, sehr geehrter Herr Kollege,}

Mitte November hatte der Thieme Verlag zu einer Sitzung der herausgebenden Fachgesellschaften der FTR nach Zürich eingeladen, dort waren wir Gäste von Prof. Oliver Ullrich, Deutsche Gesellschaft für Luft- und Raumfahrtmedizin. Beim Aufstieg zur Universität entdeckte ich den Hinweis auf das reisemedizinische Zentrum der Universität. In Deutschland sind wir derzeit von einer solchen (selbstverständlichen?) Präsenz in der Öffentlichkeit noch ein Stück weit entfernt, ebenso von einer breiteren universitären Institutionalisierung.

Von der genannten Besprechung bringe ich folgende Bitte mit: Für die jährlichen 6 Ausgaben der FTR besteht immer ein Bedarf an Kasuistiken aus der reisemedizinischen Praxis und Fachaufsätzen aus dem großen Spektrum reisemedizinischer Themen. Häufig fokussieren wir dabei infektiologische Themen. Nicht übertragbare Erkrankungen finden nicht die gebührende Aufmerksamkeit.

Ein besonderer Dank deshalb an meinen Studienkollegen Gerd Laux für seine Übersicht zu psychischen Erkrankungen im Kontext einer Reise in dieser Ausgabe.

Für das kommende Jahr die herzliche Bitte des Vorstands: Bitte überlegen Sie, ob Sie nicht einen interessanten Fall aus Ihrer Praxis vorstellen wollen; Teilnehmer unserer Jahrestagungen wissen, wie lehr- reich und unterhaltsam die Fallvorstellungen sind, die von Rose Mazzola jeweils an den Beginn des wissenschaftlichen Programms gestellt werden. Falls Sie einen Koautor suchen, sollte sich im Umfeld des Vorstands jemand finden lassen, der Sie gegebenenfalls bei der Bereitstellung von Fachliteratur und/oder Recherche unterstützen kann. Hilfestellung kann die DFR auch geben, wenn Sie für eine reisemedizinische Fortbildung, die Sie der Ärzteschaft vor Ort vorschlagen wollen, eine Referentin/einen Referenten suchen.

Im Namen des Vorstands darf ich Ihnen zum Jahresende für Ihre Mitarbeit in Arbeitskreisen der DFR, Ihre vielfältigen Vorschläge und Anregungen sowie Ihr anhaltendes Interesse an unserer Jahrestagung sehr herzlich danken.

Für die kommenden Weihnachtsfeiertage und den Jahreswechsel die besten Wünsche des Vorstands und der Geschäftsstelle.

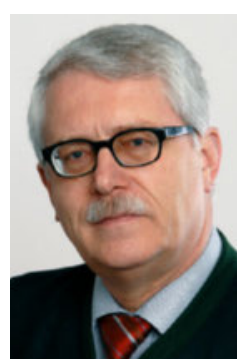

Herzlichst

Ihr

Günter Schmolz, Bietigheim-Bissingen/ Düsseldorf

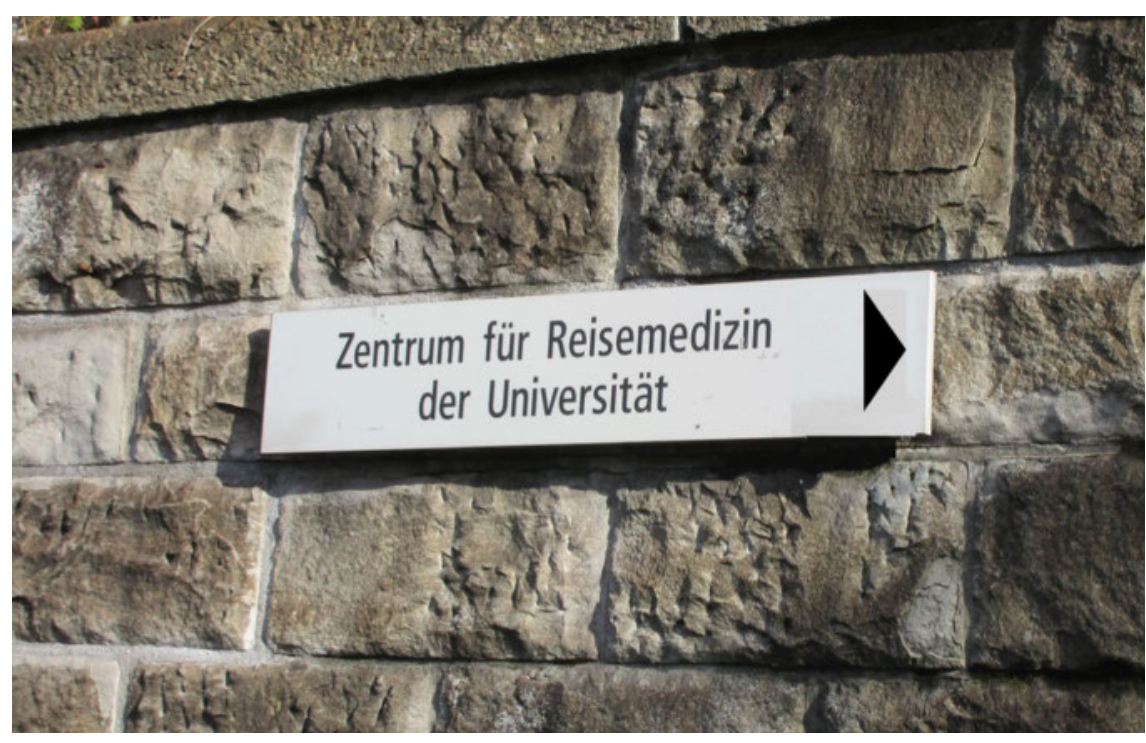

DEUTSCHE FACHGESELLSCHAFT

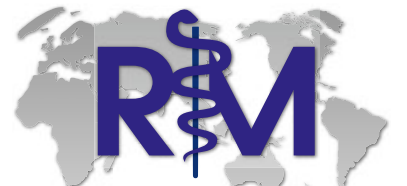

für REISEMEDIZIN e.v.

German Society for Travel Medicine

Verantwortlich für die DFR-Fachgesellschaftsseiten: Prof. Dr. Günter Schmolz, Bietigheim-Bissingen (V.i.S.d.P.)

Hansaallee 299, 40549 Düsseldorf Tel.: 0211/5202581 Fax: 0211/5202583

E-Mail: info@fachgesellschaft-reisemedizin.de www.fachgesellschaft-reisemedizin.de
Zürich - am Aufgang zur Universität: Ein bemerkenswerter Service für die Einwohner von Zürich und Umgebung. 